Journal of Contemporary Educational Research

Research Article

\title{
Intercultural Communication and Mutual Learning From Movies -Taking Coco as an example
}

\author{
Hairong Sun ${ }^{1 *}$, Xuezhu Zhang ${ }^{2}$ \\ ${ }^{1}$ Beijing Information Technology Academy, Beijing 100015, China. \\ ${ }^{2}$ Hunan University of Science and Technology, Xiangtan 411201, Hunan Province, China
}

\begin{abstract}
Based on the five elements of communication, this article analyzes the key elements of intercultural communication of films with Coco as a good example. It notes that in the modern globalization, all countries should continuously promote cultural communication, learn from each other, and promote the progress of the world as a whole. One way of achieving this is to make full use of new media and continuously explore new forms of intercultural communication, strengthen researches on intercultural communication, and resolve cultural differences. What's more, each country should build on its own cultural identity and confidently disseminate its national culture. Only in these ways, can the human community of common destiny be consolidated, can the world be peaceful and prosperous.
\end{abstract}

Keywords: Inter-cultural communication; Film; New media; National culture

Publication date: August, 2020

Publication online: 31 August, 2020

*Corresponding author: Hairong Sun,sunhr@bitc.edu.cn

On October 20, 2017, the movie Coco was released at the Morelia International Film Festival in Mexico.

In just one week, the film became the highest-grossing animated film in Mexico. Within a month, the movie became the highest-grossing film in Mexico's history. Still more good news came from the Chinese market across the ocean: the movie Coco became one of Pixar's best-selling movies in China, bringing more than 70 million dollars in box office returns, greatly exceeding Pixar's original estimated box office return of 30 to 40 million, which doubles the box office of its previous documentary, Finding Nemo! So what has contributed to the successful intercultural communication of the movie Coco ? And what secret power has turned it into a dark horse in the film industry?

\section{Intercultural Communication}

Communication is the transmission of social information and the operation of social information systems. It consists of five elements: information source, information destination, media, message, and feedback. Information source refers to the sender of information; information destination refers to the receiver of the information while media refers to the channel, means or tools of communication. Intercultural communication occurs when individuals, groups or organizations with different cultural backgrounds try to communicate. Throughout history, there are numerous great examples of intercultural communication, for instance Xuan Zang's Journey to India, Monk Jian Zhen's Journey to Japan, Zheng He's Voyage, and Marco Polo in China, to name just a few. At that time, to communicate with people from another culture, one needed to cross thousands of mountains and rivers. However, via modern technology, nowadays people can communicate with the world without leaving one's home. Actually, intercultural communication has become part of life for people in the global village ${ }^{[1]}$.

With the growing trend of globalization, cooperation among countries is becoming increasingly popular, economic and trading exchanges have soared in the last decades. What's more, the rapid development of new media such as satellite communications and networks has powered cultural communication and information exchanges among different countries. As 
Frederick described in Global communication and international relations: the world has become a multiple organism connected by all kinds of information. It's filled with enormous data which acts as blood vessel, with submarine cables and satellite networks which function like artery. Every day, the organism is full of hundreds of hours of TV programs and large amounts of information. Coco, the eye-catching film, is a message that Pixar (information source) has used the interactive feedback from the world's huge information organism: film and television media, online media, and movie viewers. Based on its unique cultural connotation, the interaction through the media has aroused a stirrng effect.

\section{A Study of the Movie Coco Promotion}

\subsection{Perfec media promotion}

In addition to traditional propaganda on media like newspapers, magazines and TV, Pixar also launched Cосо VR, a virtual project before the release of the film, which allows the users to experience the magic world of the Dead in advance. It goes without saying that this VR experience has played a great role in appealing to the audience and make it better known.

Meanwhile, other factors also contributed to the success of the promotion - it was released at the right time in the right place for the right audience. The reason why Pixar chose to release Coco in Mexico on October 20, 2017 is to take advantage of the Mexican International Film Festival; and the memorial day of the Dead, that is, $1^{\text {st }}$ and $2^{\text {nd }}$ of November. It is wellknown that the Day of the Dead is important festival in Mexico. As Octavio Paz, the winner of Nobel Prize in literature said, "Death is not often mentioned by New Yorkers or Londoners. But Mexicans often talk about death, laugh at it, dream about it, and even celebrate it. For Mexicans, death is sth like a toy. Based on a deep understanding of Mexican culture, Pixar grasped the golden opportunity of the Day of the Dead, which made the promotion in Mexico successful. A month after its release, the movie Coco has more than 2,000 reports from various news media, and has received over 3,700 positive reviews in Douban movie lists. These satisfying numbers account for the indispensable fifth element of communication---feedback.

\subsection{Brilliant messages}

\subsubsection{Exotic interpretation of familiar topics}

The film not only has connected the Day of the Dead with the audience's experience, but also evoked a wave of cultural shocks. Its profound Mexican culture and interesting customs have brought lots of surprises to Chinese audience. The fantastic golden marigold bridge is the way to connect the living and the dead. The terrifying matters is turned into "sweet skull", and the enthusiastic Papel Picardo's paper-cutting makes Chinese audience feel completely different. The movie also has showed the Chinese two wonderful worlds which formed great contrast to each other: one is the Land of the Living which is warm, full of life, love and family. The other is the land of the dead, a blue and purple world. These two worlds are balanced, interdependent and mutually reinforcing.

The Mexicans celebrate Life Cycle happily at the Day of the Dead, singing and dancing to welcome the returning dead while China's Day of the Dead -"TombSweeping Day" is featured with drizzles or rains that fall like tears on the Mourning Day; The Chinese mourner's heart is going to break on this day. Why is there such a big difference? Well, the reason lies deeply in the culture. As we know, the Mexican Day of the Dead is a combination of Indian and Spanish cultures .It dates back to a history of at least 3000 years. Back then, people believed that after death, one would experience a long journey to Mitland, the world in which people lived after death. Only on the Day of the Dead could the dead return to the world to meet their living relatives ${ }^{[2]}$. So for Mexicans, death is not an end, but a new beginning. Therefore, the return of the dead has become a celebrating day for the family. On the contrary, TombSweeping Day in China is closely related to the Cold Food Festival. In the old days, people banned fire and had cold food for a day or two before Tomb-Sweeping Day. According to the legend, it was a tradition in memory of Jie Zitui during the Spring and Autumn Period. Once Chonger, the Pricess of Jin, was exiled and nearly starved to death, Jie Zitui cut meat from his leg and made soup for Chonger. Later, Chonger became the monarch but Jie Zitui resigned and lived in seclusion with his mother. In memory of Jie Zitui, Chonger commanded this day to be Cold Food Festival. Later, the day after the Cold Food Festival was ordered as the Tomb-Sweeping Day. So death is a heavy topic for the Chinese. From these we can learn that these two different cultures have caused different views on life and death.

In the movie Coco, Chinese audience can also spot some familiar images. For example, to welcome the returning dead, Mexicans will set up altars in their homes, display photos of the dead and worship them with water, fruits, paper cuttings, candles, etc. The 
water is to feed them coming from afar. Fruit stand is also supposed to be used by the dead. Paper-cutting stands for wind. The candle stands for fire, symbolizing light and hope. These are similar to China's previous sacrifices. However, the symbols of wind, fire and soil are completely different from China's metal, wood water, fire, earth. All of these create certain connection with the Chinese audience, but at the same time these brings a completely new experience. These also reflect the beauty of cultural diversity.

\subsubsection{Generalization of the beloved themes}

If the Day of the Dead allows us to see the beauty of the diversity of culture, then the theme of the film(dream \& love) is so breathtaking that it moves people from various countries. Miguel is not beaten with his perseverance and hard work. Grandma Coco never forgets his father Ector, the living cannot forget the dead, all of these are common emotions for people from various cultures and eras. In the film, the four generations of Miguel's family share many joys and happiness, and their strong and warm feelings have deeply touched audience across the world.

The movie Coco has impressed both the local and world-wide audience by its integration of love and dream. At the era of globalization, we need to strengthen cultural communication, promote mutual understanding, and constantly promote mutual learning between different civilizations. This is the humanistic basis for building a community with shared future, a bridge for enhancing friendship among people of all countries, a motivator for the progress of human society, and a bond for maintaining the world peace.

\section{Inspirations from the movie Coco}

\subsection{Be a good story-teller of Chinese culture}

China is a country with profound culture and is full of wonderful stories like Coco. These wonderful stories and cultural elements have been adapted by other countries repeatedly. A case in point is Japanese's using Chinese elements in its animation products. For example, Toriyama Akira, the famous Japanese animation master used the image of Sun Wukong in his work Dragon Ball. Dragon Ball was first produced as a TV animation and released on Fuji TV in Japan, and later it was derived from theatrical version of animation, Hollywood movies, and many peripheral products and gaming software. Therefore, Dragon Ball is a case of opening up the international market through cultural learning.
Kung Fu Panda is a Hollywood movie, issued in 2008, featuring the image of panda, the national treasure of China and the profound martial arts, which has caused a heated response worldwide. In the film, the mighty tiger boxing, the swift monkey boxing, the elegant crane boxing, the agile snake boxing, and the rigid and flexible mantis boxing are all designed in fancy ways ${ }^{[3]}$. However, for many foreign film companies, China's elements are just a stepping stone to open the Chinese market. In fact, what they concentrate more on is the huge potential of China's market. Tian Huiqun, a doctor of film science at Beijing Normal University, once commented that no matter how many Chinese elements are in a Hollywood movie, it always tells about the American stories and always reflects the American values. There will be misunderstandings in the interpretation and presentation of different values and moral views behind China's elements.

It is known that different values and morals have their political attributes. As Schiller noted, "Films, radios and television shows, books, reports and other cultural products or services can provide not only information and entertainment, but also tools for diffusing social values or political opinions." This circuitous way to achieve purpose is the second face of power: behind the influence of the culture and values is the ability to influence and shape the will of others, which is called "a invisible hand", as well as "the soft power" of a country ${ }^{[4]}$. This shows that cross-cultural communication is indeed a double-edged sword, on one hand it can promote exchanges among different cultures; on the other hand, it can bring about cultural conflicts. A stronger country in communication will not only cause image damage to weaker countries, but also cause certain cultural invasions.

The unique national culture is a world-wide identity for a country. And it is the source of self-confidence and faith for the people. As for Chinese, we treasure the character of benevolence, the principle of harmonious interaction and the behavior of mutual respect, which have become the world-wide consensus. China's splendid traditional culture and its national spirit not only created a great historic China, but also gave birth to a promising future for China. Therefore, we must strengthen cultural self-confidence, tell our stories, speak on the international stage, and present an objective, true, comprehensive and modern China to the world.

\subsection{Make the best of new media to promote communication}

From the birth of a language to information 
age, communication has gone through stages of oral communication, text communication, print communication, and electronic communication. Finally, they all merge into the information highway. From ordinary phones to smart phones, from snail mail to email, communicating technology has been developed astonishingly. Generally speaking, new media refers to media that functions on IT science, using digital, network, and mobile technologies to deliver messages to receivers. Through the Internet, wireless communication networks, satellites and other channels, and terminals such as computers, mobile phones, and digital televisions, new media provides users with information and entertainment services. In the 21 st century, various streaming media and wemedia have emerged continuously. Unlike traditional media communication, the communication tools of the new streaming media are no longer in the charge of individual organizations or institutions. Everyone has the ability to create and disseminate the content ${ }^{[5]}$. The word "audience" has double meanings of information producer and consumer.

With the rapid development of media technology, producer and consumer has become "prosumer".

With its nature of virtuality, shareability, and interaction, network enables different groups to exchange information at any time, at any place, which results in a more multi-dimensional communication relationship.

Take the British BBC TV Peppa Pig as an example: In October, 2015, Peppa Pig was launched on three major video platforms such as IQiyi, Youku and Tudou in China. In just one year, the number of viewers reached more than 10 billion, which has brought a powerful economy of attention. Meanwhile, with the help of the Quick Worker, Tik Tok, podcasts and other platforms, Peppa Pig has become a money-making pig.

Data shows that the searching volume of Peppa Pig on Tmall in March 2018 increased by 5 times, reaching nearly 20 million compared with that in February, 2018. In April, the searching volume reached more than 2,000 Million. Tmall sold 3.03 million pieces of Peppa Pig's IP pants at Double Eleven, 2019, which confirms the American communication scholar Bodrial's assertion of the symbolization of consumption, that is, the consumption in modern society has actually exceeded meeting the actual needs. What's more, Peppa Pig has become a symbol; it has evolved from a simple animated character to a phenomenon of communication.

\subsection{Respect each other's culture and enhance intercultural communication}

UNESCO defines interculturality as the existence and equal interaction of different cultures and the possibility of generating common cultural expressions through dialogues and respect. Culture is a combination of material and spiritual products in human society. Different nations have different languages and different cultures, which influence people's clothing, food, shelter, etiquette, customs, aesthetic taste, value orientation, and so on. When people of different cultures meet, they should recognize differences and respect each other, create a connection in the interaction through dialogues, so as to achieve mutual understanding.

The movie Zootopia has set a good example of intercultural communication by mirroring cultures of different countries. For instance, the Sports Hall of the Glacier Town features a Russian onion-shaped dome. The indoor tropical garden of the train station is a copy of Madrid Central Station in Spain. The climate of Animal City is similar to Southern California ${ }^{[6]}$. Also, it is worth mentioning that even the image of the newscaster in the film is varying in accordance with the issuing place of the film, and localized iconic animals such as China's panda, Australian koala, Brazilian puma, and British corgi Pembroke are used respectively. When it was issued in China on Chinese New Year, the filmmaker chose to release posters of animal stars sending blessings such as being cheerful and confident, realizing one's ambitions, and good wishes of making fortune in the new year. All these have appealed to the audience greatly.

Undoubtedly, due to differences in cultures and values, due to language barriers, misunderstanding may occur in intercultural communication. For instance, wearing mask is viewed as a good way to prevent Covid-19 in Asia while it is regarded as being sick or useless in America at the first half year of 2020 . Therefore, researches in intercultural communication should make great efforts studying local ideology , taboos and social lifestyles. We should develop a suitable cultural communication strategy that is accordance with the local development. Only in this way can we succeed in intercultural communication.

Culture and civilization are enriched through exchange and mutual learning. Civilization is diversified, just like the diversity of natural species, which form the origin of life on the earth ${ }^{[7]}$. Cultural diversity will also make this world more colorful. The $21 \mathrm{st}$ century is an era of increasingly global cooperation, an era of mutual integration, and an era in which new and old media meet and interact with each other. We need to make full use of new media and continue to explore new ways and channels for the communication of our national 
culture $^{[8]}$. We need to enhance cultural self-confidence, tell Chinese stories on the international stage, and shoulder more responsibilities in international affairs ${ }^{[9]}$. As an old Chinese saying goes, "A single flower does not make a spring. " Only when the countries in the world can learn from each other and foster a common ground of cooperation, can it become the consensus of the whole world to achieve the prosperity and progress of the human civilization ${ }^{[10]}$ !

\section{References:}

[1] Available from: URL: https://baike.sogou.com/v5843860.htm?fromTitle=Intercultural Communication.

[2] Jia C. Greetings for the dead - Mexica's Day of the Dead[J]. Garden of Science, 2007(14): 40-41.

[3] Luo TY, Zhong Yuanbo. Analysis on Multi-dimensional Inter- pretation of Chinese elements of Hollywood's "Kung Fu Panda"[J]. Film Review, 2008(19).

[4] [US] Joseph. Soft Power[M]. Translated by Ma Juanjuan, CITIC, 2014.

[5] Mayfield, Antony. What Is Social Media?. Cited May 7, 2013; 1(1): 24 screens. Available from: URL: http: //www.antonymayfield.com/2008/03/22/what-issocial-media-ebook-on -mashable/.

[6] https://www.1905.com/newgallery/hdpic/975005.shtm1\#p3: Zootopia.

[7] Xi JP. Speech at the League of Arab States Headquarters, 2016.1.

[8] Zhang L. Research on Intercultural Communication of Media Discourse[J]. Northern Discussions, 2013, 4

[9] Guo QG. Course of Communication Studies[M]. Renmin University of China Press, 2001.

[10][US] Richard E. Porter. Cross-cultural communication[M],Dong Xiaobo translation. Beijing: Peking University Press, 2012. 